\title{
Unusual Presentation of a Mediastinal Tumour: A Case Report
}

\section{Tushar Kumar ${ }^{1 *}$, Arindam Roy${ }^{1}$, Prerit Agarwal' ${ }^{1}$, Vithal Kumar M. Betigeri' ${ }^{1}$, Nishu Raj ${ }^{2}$, Ravindra Kumar Saran ${ }^{3}$}

\author{
${ }^{1}$ Department of Cardiothoracic and Vascular Surgery, Govind Ballabh Pant Institute of Post Graduate Medical Education and \\ Research, JLN Marg, New Delhi, India \\ ${ }^{2}$ Department of Radiodiagnosis, Govind Ballabh Pant Institute of Post Graduate Medical Education and Research, JLN Marg, \\ New Delhi, India \\ ${ }^{3}$ Department of Pathology, Govind Ballabh Pant Institute of Post Graduate Medical Education and Research, JLN Marg, \\ New Delhi, India \\ Email: *dr.tusharkumarpmch@gmail.com
}

How to cite this paper: Kumar, T., Roy, A., Agarwal, P., Betigeri, V.K.M., Raj, N. and Saran, R.K. (2017) Unusual Presentation of a Mediastinal Tumour: A Case Report. World Journal of Cardiovascular Diseases, 7, 367-372.

https://doi.org/10.4236/wjcd.2017.710034

Received: September 28, 2017

Accepted: October 28, 2017

Published: October 31, 2017

Copyright $\odot 2017$ by authors and Scientific Research Publishing Inc. This work is licensed under the Creative Commons Attribution International License (CC BY 4.0).

http://creativecommons.org/licenses/by/4.0/

\begin{abstract}
Neurofibroma arising from intrathoracic vagus nerve is a rare entity. We present a 6-year-old child with stigmata of neurofibromatosis along with a lump in the back. She also had history of on and off cough. On investigation there was a large mediastinal mass abutting the trachea. She underwent a posterolateral thoracotomy with partial resection of the lump. Intraoperatively the mass appeared to arise from the vagus nerve. Post operative stay was uneventful. Biopsy of the mass revealed a benign neurofibroma with no evidence of invasion. She is presently asymptomatic after 1 year of follow-up.
\end{abstract}

\section{Keywords}

Neurofibroma, Neurofibromatosis, Thoracotomy

\section{Introduction}

Mediastinal neurogenic tumors account for approximately $35 \%$ of all pediatric mediastinal neoplasms. They mostly arise from nerve cells or nerve sheath usually located in the posterior compartment. Patients with neurofibromatosis 1 have cafe au lait spots and associated manifestations involving the thorax. Here we present a large unresectable mediastinal neurofibroma with features of neurofibromatosis 1 in a 6-year-old child.

\section{Case Report}

A 6-year-old girl child presented to us with complaints of painless slowly grow- 
ing lump on right upper back since 2 years of age. It was initially noticed by her parents which gradually increased in size over a period of time. There was history of on and off dry cough. Her birth and developmental history was uneventful. No similar illness in family was noted. The general physical examination did not reveal any significant finding. A well defined immobile painless mass of size 8x 6 $\mathrm{cm}$ was palpable over the interscapular area. There were multiple café au lait spots (larger than $0.5 \mathrm{~cm}$ ) scattered over the upper back and over the surface of the lump (Figure 1). No asymmetry of the chest wall was noted. Percussion notes were impaired all over the right lung field. Breath sounds were reduced in intensity on the right inter-scapular, supra-scapular and infra-scapular areas. Examinations of the other systems revealed no abnormality (Table 1). Laboratory examination revealed a white cell count of $6.7 \times 10^{3} / \mu \mathrm{l}$ and negative $\mathrm{C}$ reactive protein. Her serum Lactate dehydrogenase levels were $194 \mathrm{U} / \mathrm{L}$ and alfa

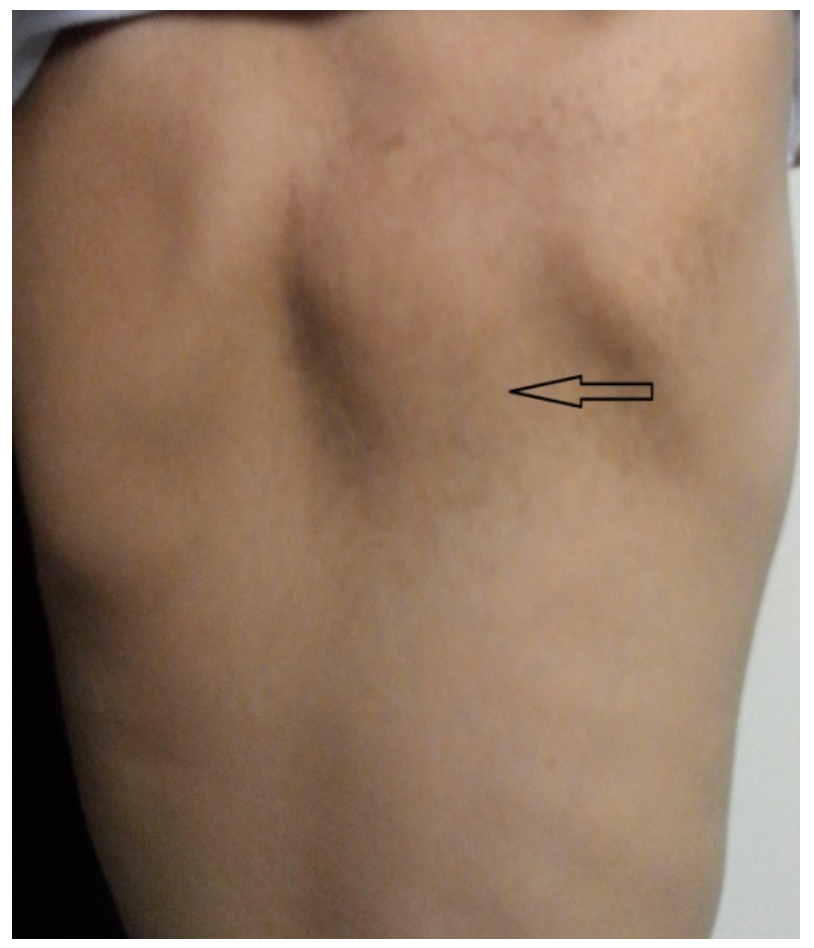

Figure 1. Preoperative photograph showing lump with cafe au lait spots over the back (black arrow).

Table 1. Sociodemographic and clinical characteristics.

\begin{tabular}{cc}
\hline Age & 6 years \\
\hline Ethnicity & Asian (indian) \\
Sex & Female \\
Socioeconomic status & Upper middle \\
Family type & Nuclear \\
Lump in back & Since 2 years of age \\
Cafe au lait spots & Upper back and over lump \\
\hline
\end{tabular}


fetoprotein of $0.9 \mathrm{mg} / \mathrm{ml}$. Chest radiography revealed a homogenous opacity in the right upper mediastinum. The trachea appeared central. A fine needle aspiration cytology revealed spindle shaped cells arranged in small groups and scattered singly suggestive of mesenchymal tumour. A magnetic resonance imaging (MRI) of dorsal spine revealed a lobulated lesion in the posterior right paraspinal region from $\mathrm{C} 7$ to $\mathrm{D} 5$ hyperintense on $\mathrm{T} 2 \mathrm{~W}$ images and hypointense on $\mathrm{T} 1 \mathrm{~W}$ image (Figure 2). It was extending into the deep subcutaneous fat with lateral extension into posterior thoracic cavity suggestive of mesenchymal tumour. There was another small lobulated lesion in the left side of the neck posterior to internal carotid artery. A 256 slice contrast enhanced computed tomography carotid angiography (CTA) revealed normal carotid vessels without any compression or invasion. Posterolaterally the mass was extending into right paraspinal muscles. Anteriorly the mass was abutting the right lateral wall of trachea, internal jugular vein, subclavian artery, superior vena cava without any thrombosis or compression. Fat planes were maintained with esophagus. Bilateral carotids and brain parenchyma appeared normal. She was planned for surgical resection based on the above findings after informed consent. The tumour mass was approached via a posterolateral thoracotomy. On entering the right pleura a non encapsulated fusiform mass was detected adjacent to the trachea (Figure 3 ). The mass was anteriorly encompassing the right vagus nerve and seemed to be originating from it. The whole tumour could not be resected so an open biopsy

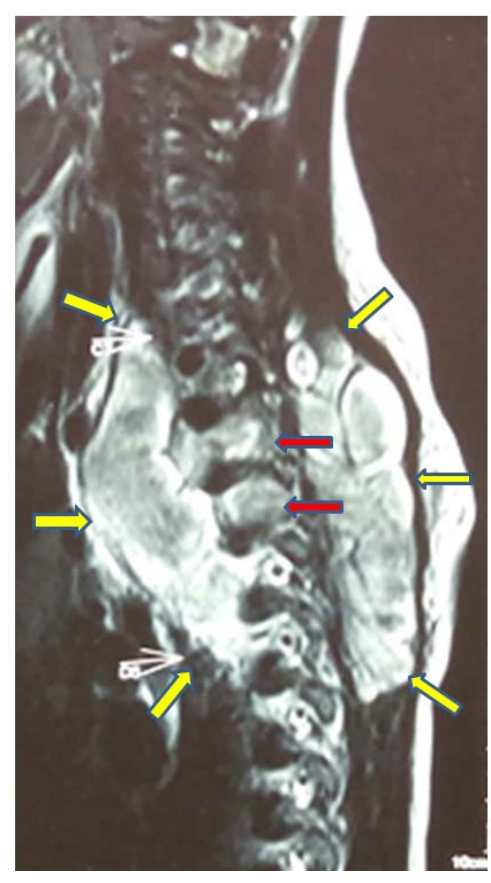

Figure 2. Right Parasaggittal T2W image showing a large hyperintense lobulated mass lesion (yellow arrows) extending from C7 to D6 vertebral level. Anteriorly it is seen extending into the thoracic cavity and posteriorly lifting the paraspinal muscles and the subcutaneous fat. Also extension through enlarged neural foraminas (red arrows) can be seen. 


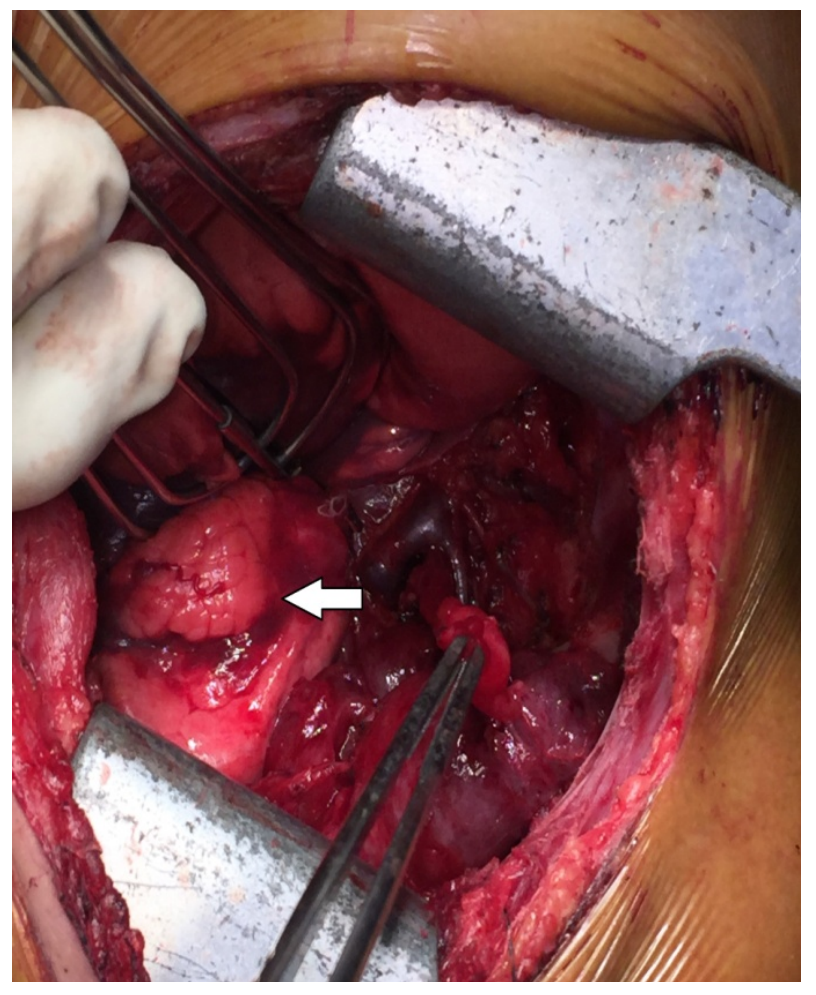

Figure 3. Intraoperative photograph showing the partially resected lump (white arrow).

was performed to prevent compression on trachea. Grossly it was spheroidal in shape, soft and white in colour. On cut surface, it was grey and rubbery in texture except for focal areas of gritty calcification. Microscopic examination revealed benign spindle cells with curved nuclei along with presence of fibroblasts in collagenous to myxoid matrix present in the form of well defined lobules. The nuclei were elongated with wavy, serpentine configuration and had pointed ends with moderate amount of eosinophilic cytoplasm with no evidence of mitotic activity or necrosis. Blood vessels showed hyalinisation. It was positive for S-100 stain (Figure 4). Features were consistent with a neurofibroma. Post operative stay was uneventful. Her post operative MRI of dorsal spine revealed no intrathoracic lesion with irregular lesion in right paraspinal region (Figure 5). She is in regular follow-up with no fresh complaints.

\section{Discussion}

Neurofibroma accounts for $4 \%$ of all mediastinal tumors. Neurofibroma with NF1 is associated in less than $1 \%$ of all cases [1]. However, it is estimated that $4.5 \%$ of NF1 patients develop mediastinal tumors [2]. Neurofibroma of the intrathoracic vagusnerve is a benign, slow-growing neurogenic tumor that arises from the nerve sheath. These tumors can occur in any location in the thorax, although they most commonly develop adjacent to ribs, in the paravertebral region and within the mediastinum [3]. Our patient in this case presented with a lump in the back. 


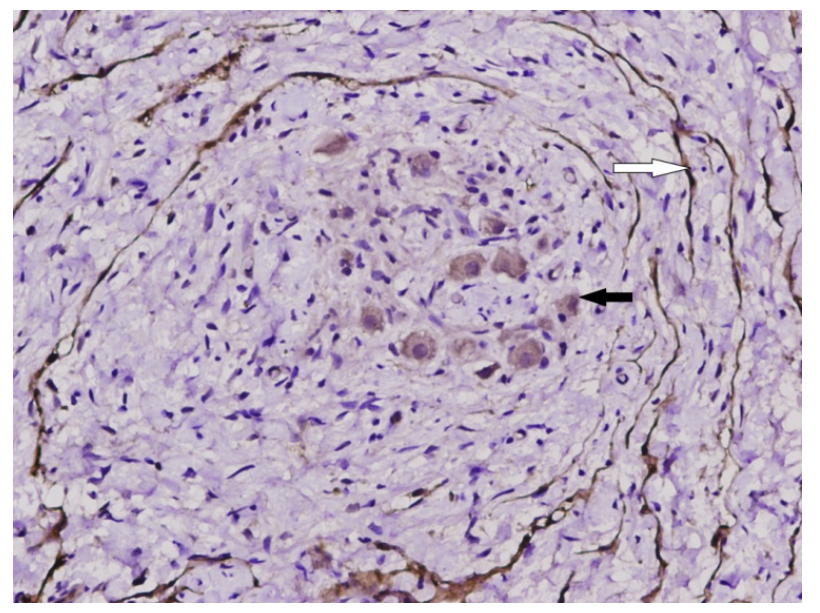

Figure 4. Sample stained with S-100 stain ( $2 \times$ magnification) showing positive staining for spindle cells with elongated nuclei (white arrow) and fibroblasts with oval nuclei (black arrow).

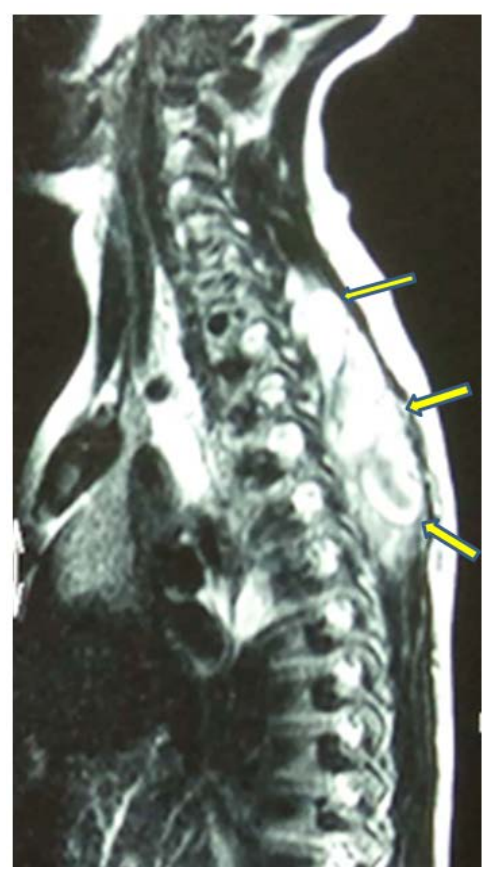

Figure 5. Post op right parsaggittal image of the same patient showing no intrathoracic lesion. Residual lesion (yellow arrows ) is seen posteriorly.

There are very few case reports of intrathoracic vagus nerve neurofibroma, since most of them arise from intercostals and sympathetic trunk. In this case the tumour had no connection to the mediastinum other than the right vagus nerve, which entered superiorly and exited inferiorly. Also it was difficult to debulk the whole tumour due to its proximity to esophagus, trachea and the aorta. Resection of the tumour necessitated sacrifice of the vagus. Hence a decision was taken to partially resect the tumour without damaging the surrounding structures and nerve with the aim to reach at a tissue diagnosis. Unlike the schwan- 
noma, neurofibroma is nonencapsulated tumor, making it impossible to completely excise the tumor and preserve the nerve [4]. Very few studies support complete respectability of such tumours in a NF 1 patient. Complete surgical excision is usually recommended for these nerve tumors [5].

The treatment of choice of any intrathoracic vagal tumours is surgical removal [6]. Only by thoracic exploration and excision can the diagnosis be made accurately and malignancy excluded. Removal of the tumour necessitates sacrifice of the vagus nerve; however, resulting dysfunction to the heart, bronchial muscles, and gastrointestinal tract has not been observed. Sacrifice of the vagus nerve results in vocal cord paralysis only when the tumour is located proximal to the take-off of the recurrent laryngeal nerve.

It is important to determine the benefit risk ratio associated with complete versus a partial resection. The motive is to prevent injury to the vital structures and help to reach at a diagnosis. Medical treatment using antiangiogenic drugs and farnesyl transferase inhibitors have been evaluated [7]. Since they have an unpredictable natural history a suuden increase in size, pain or a neurological deficit should be viewed with suspicion of malignant transformation of the neurofibroma and a open tissue biopsy should be obtained.

\section{Funding}

There is no support in the form of grants, equipments, drugs for this article.

There is no financial or material support for this article.

\section{References}

[1] Wychulis, A.R., Payne, W.S., Clagett, O.T., et al. (1971) Surgical Treatment of Mediastinal Tumors: A 40-Year Experience. The Journal of Thoracic and Cardiovascular Surgery, 62, 379-392.

[2] Valeyrie-Allanore, L., Ismaili, N., Bastuji-Garin, S., Zeller, J., Wechsler, J., Revuz, J. and Wolkenstein, P. (2005) Symptoms Associated with Malignancy of Peripheral Nerve Sheath Tumours: A Retrospective Study of 69 Patients with Neurofibromatosis 1. British Journal of Dermatology, 153, 79-82. https://doi.org/10.1111/j.1365-2133.2005.06558.x

[3] Feldkamp, M.M., Gutmann, D.H. and Guha, A. (1998) Neurofibromatosis Type 1: Piecing the Puzzle Together. Canadian Journal of Neurological Sciences, 25, 181-191. https://doi.org/10.1017/S0317167100033990

[4] Uchida, K., Okada, T., Honda, S., Miyagi, H., Kobayashi, R., et al. (2012) Giant Mediastinal Neurofibroma in a Child withNeurofibromatosis Type I. Surgical Science, 3, 564-567.

[5] Smahi, M., Lakranbi, M., Ouadnouni, Y., et al. (2011) Intrathoracic Phrenic NerveNeurofibroma. The Annals of Thoracic Surgery, 91, e57-e58.

https://doi.org/10.1016/j.athoracsur.2010.11.028

[6] Osada, H., Funaki, S., Okada, T., et al. (1979) A Case Report of Intrathoracic Vagal Schwannoma. Kyobu Geka, 32, 303-306.

[7] Packer, R.J., Gutmann, D.H., Rubenstein, A., Viskochil, D., Zimmerman, R.A. and Vezina, G. (2002) Plexiform Neurofibromas in NF1: Toward Biologic-Based Therapy. Neurology, 58, 1461-1470. https://doi.org/10.1212/WNL.58.10.1461 